\title{
Исследование влияния температуры на характеристики пьезооптических датчиков механических напряжений
}

\author{
П. С. Загубисало ${ }^{1)}$, А. Г. Паулиш ${ }^{1,2}$ \\ ${ }^{1}$ Новосибирский филиал Института физики полупроводников им. А. В. Ржанова СО РАН \\ «Конструкторско-технологический институт прикладной микроэлектроники», \\ 630090, г. Новосибирск, просп. Академика Лаврентьева, 2/1 \\ ${ }^{2}$ Новосибирский государственный технический университет, 630073, г. Новосибирск, просп. К. \\ Маркса, 20 \\ тел:+ 7 (383) 330-97-49, внут. номер 365, эл. почта: peter.zagubisalo@gmail.com
}

DOI 10.34077/RCSP2019-179

Отрицательное влияние температуры на характеристики датчиков разных видов является общей проблемой, с необходимостью решения которой сталкиваются все разработчики датчиков. Эта проблема актуальна и для датчиков механических напряжению любого типа: тензорезисторных, волоконно-оптических и пьезоэлектрических. Изменение температуры приводит к изменениям чувствительности датчика, дрейфу нуля, снижению точности. Недавно был предложен новые датчики деформаций на основе пьезооптического эффекта, которые отличается от других более чем на три порядка бо́льшим коэффициентом тензочувствительности [1]. Тем не менее, этим датчикам также присущи зависимости характеристик от температуры. Исследование причин возникновения данных зависимостей было проведено теоретически, с помощью численного моделирования и экспериментально. Теоретический анализ показал, что параметры оптических элементов пьезооптического датчика (свойства поляризаторов и анализаторов, коэффициенты преломления слюды и плавленого кварца, модуль Юнга и пьезооптический коэффициент кварца) практически не зависят от температуры в диапазоне $-40-$ $+50^{\circ} \mathrm{C}$. Исключение составляет длина волны излучения фотодиода (660 нм), которая меняется на $~ 15$ нм. Это изменение относительно слабо влияет на выходной сигнал и не объясняет экспериментальные данные.

Численное моделирование напряжений возникающих в системе датчик-адаптивный элемент-контролируемый объект при изменении температуры показало существенную температурную зависимость величины напряжений на датчике из-за асимметрии контролируемого объекта. Если симметрия объекта отличается от осесимметричной, то в нём возникают несимметричные напряжения, которые и фиксирует датчик. Поэтому одной из причин температурных зависимостей показаний датчика является сам объект контроля, что нужно учитывать при монтаже датчика и его эксплуатации. Численное моделирование преобразований фазы и амплитуды световой волны при прохождении оптических элементов пьезооптического преобразователя было
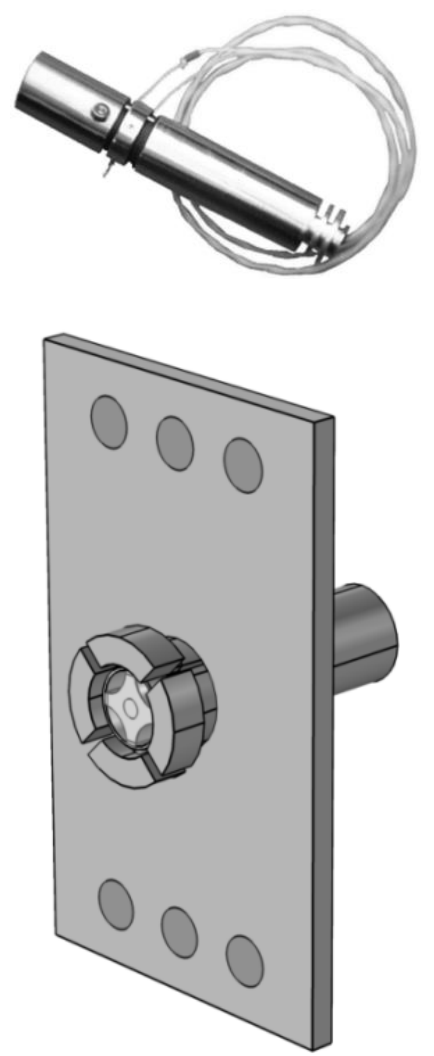
выполнено методом матричной алгебры с использованием матриц Мюллера и параметров Стокса. Моделирование показало, что температурная зависимость выходного сигнала датчика возникает в случае неточности установки оптических осей одновременно двух или более элементов схемы. В результате моделирование позволило определить допуски на точность установки элементов оптической схемы, изменить конструкцию датчика и существенно снизить влияние температуры на его характеристики.

\section{Лumepamypa}

[1] Paulish A. G., Zagubisalo P. S., Barakov V. N., Pavlov M. A., Poyarkov A. V. Piezo-optical transducer for high sensitive strain gauges // IEEE Sensors J. 2018. 18, N. 20. P. 8318-8328. 